Bjørn Håland is Associate professor at Department of Education, University of Stavanger, Norway. His master's degree and $\mathrm{PhD}$ is on botanical ecology, both from University of Bergen. All together he has worked 13 years in teacher education at Notodden and 12 years in Stavanger, mainly with chemistry and biology. Science education research is an important area of interest. In the years $1984-87$ he worked 3 years as a researcher at Norwegian institute of forest research at Ås.

BJØRN HALAND

Department of Education

University of Stavanger

Norway

e-mail:bjorn.haland@uis.no

\title{
Student teacher conceptions of matter and substances - evaporation and dew formation
}

\author{
Abstract \\ It is observed that student teachers have problems with seemingly simple ideas in introductory \\ chemistry. In order to uncover possible underlying problems, a rather comprehensive investigation on \\ their views on matter, substances and the particulate view of matter, was accomplished.
}

31 students were interviewed before they started on an introductory course in chemistry. The interviews were semi-structured and linked to a sorting task and some demonstrations.

All the interviews were tape-recorded and some photos were taken.

This paper reports on the students' views on evaporation and dew formation and discusses what their statements on these phenomena tell us about their general view on matter, substances and the particulate view of matter. Their statements about evaporation and dew formation are compared.

Only 6/31 students displayed a reasonably good understanding of both evaporation and dew formation, and only two of these used a more "advanced" particulate model in their explanation of both phenomena. Most of the other students hold some sensible views and some alternative non-scientific views. All measure of understanding was revealed, from almost total ignorance to an almost complete understanding. At least 4/5 of the students seem to have some problem with the concepts of matter, substance and the particulate view of matter. These concepts, therefore, clearly need to be included and addressed in an understandable way in Norwegian teacher education.

\section{INTRODUCTION}

Student teachers' problems with seemingly simple ideas in introductory chemistry have always intrigued me. Introductory chemistry seems to be a worldwide problem that researchers have wrestled with for many years (e.g. Andersson, 1990; de Vos \& Verdonk, 1985; Johnson, 2000; Nakhleh, 1992). From a human constructivist point of view (Ausubel, Novak, \& Hanesian, 1978; Novak, 1993 ) it is interesting to single out which ideas and concepts that are problematic to the students, and what kind of notions they have about these ideas and concepts, before a course starts. Only then one can pick out the "relevant anchoring concepts available in the learner's cognitive structure" (Ausubel, et al., 1978, p. 358) and try to make the teaching meaningful. 
In introductory chemistry the particulate view of matter was early singled out as a key problem (e.g. Nakhleh, 1994b; Nussbaum \& Novick, 1981), in addition to chemical reactions (e.g. Andersson, 1990; de Vos \& Verdonk, 1985; Johnson, 2000), phase changes (e.g. Andersson, 1990; Stavy, 1990; Stavy \& Stachel, 1985) and the gaseous state (e.g. Johnson, 1998b; Stavy, 1988).

Recently two more concepts that are perhaps even more fundamental, have been added to the list: the concept of matter (Nakhleh, Samarapungavan, \& Saglam, 2005; Stavy, 1991) and the concept of a substance (Johnson, 1996, 2005). An interesting aspect in this connection is Johnson's (1998b, 2002) findings that some understanding of the particulate view of matter seems necessary to understand all these key concepts and vice versa.

If one, as a teacher, wrongly assumes that the students understand and use the above mentioned key concepts in the same way as oneself, one most probably has a crucial communication problem (Johnson \& Gott, 1996). For students that understand and use these concepts differently, major parts of the chemistry teaching must be a mystery, and they are left with only one option: rote learning.

A prerequisite for proper handling of these problems in the school is that the teachers themselves understand these concepts properly and that teacher education addresses it in a relevant way. In order to uncover possible problems tied to the concepts of matter and substances and the particulate view of matter among student teachers, an investigation was done to bring forward some knowledge about what Norwegian student teachers think about these concepts, and to what extent they use a particulate view of matter when they try to explain physical and chemical phenomena.

The focus of this paper is the student teachers' ideas about evaporation and dew formation. The research questions were:

- What problems do student teachers have with evaporation and dew formation?

-What do their explanations on these phenomena tell us about their conceptions of matter, substances and the particulate view of matter, and do they use the same ideas for scientifically similar problems?

- Can their problems to some extent be linked to their conceptions of matter, substances and the particulate view of matter?

-What problem areas need special attention in further introductory courses in chemistry?

Several authors have summed up and discussed earlier investigations concerning evaporation (e.g. Andersson, 1990; Andersson, 2000; Driver, Squires, Rushworth, \& Wood-Robinson, 1994; Johnson, 1998b; Lindner, 2007; Tytler, Prain, \& Peterson, 2007). With some variation, most of them seem to conclude that it is possible to distinguish four main views: 1) for some reason the water disappears or is sucked into the material, 2) it goes via the air to walls, ceilings or the clouds, 3) it goes into the air, with various non-scientific explanations, 4) the water is changed into vapor as invisible molecules and goes into the air. The first three explanations are (mostly) macroscopic.

Andersson $(1990,2000)$ concludes that the results can be summarized with the four concepts: displacement, modification, transmutation (include disappearance) and chemical reaction. Indirectly he is saying that students do not differentiate between physical processes and chemical reactions. Modification is the right alternative in connection with evaporation. The other alternatives reveal that the students either think the substance disappears, moves unaltered or they do not conserve the substance.

Students' views on dew formation in open systems seem less investigated than evaporation (Bar \& Travis, 1991; Chang, 1999; Gopal, Kleinsmidt, Case, \& Musonge, 2004; Johnson, 1998b, 2000; Osborne \& Cosgrove, 1983). The reason might be a focus on evaporation in textbooks. They just "browse over condensation as an after thought" (Gopal, et al., 2004, p. 1616). 
The children's / students' view on condensation seems to group around 5 main ideas: a) Invisible water or vapor in the air is changed into water, b) the coldness is changed into water or cold and heat react to produce water, c) air is changed into water when cooled, d) when cooled, hydrogen and oxygen in the air react to produce water, e) water from the inside penetrate the wall of the container.

The above review shows that younger pupils and students have many problems with these phenomena. It is generally recognized that adults often have the same problems as younger pupils. Many of the findings of this paper could therefore, in theory, be inferred from the literature. If, on the other hand, this only exists as an assumption among those few that know the literature well, and if no one puts "hard facts" on the table, it would hardly have any practical impact on introductory chemistry courses for student teacher in colleges and universities. To my knowledge this is the first investigation concerning these matters among student teachers in the Nordic countries, and only one of the reviewed articles above addresses student teachers (Johnson, 2000).

Johnson (e.g. Johnson, 1996, 2005) has argued that understanding of the concept of substance is central for all chemistry understanding, a finding that ought to be examined further by other researchers. This work contributes to this by having a focus on Norwegian student teachers' views on substances and matter.

In contrast to most of the reviewed articles this investigation addresses several phenomena in the same interview. This gives the possibility to make comparisons between the views on different phenomena and investigate to what extent the students use their views consistently across relating phenomena.

\section{Methods}

At University of Stavanger the student teachers can optionally choose to include $30+30$ credits (ECTS) science as part of their education. Introductory chemistry (10 ECTS), is one module within this science education. A sample of 31 student teachers were interviewed before they started the introductory chemistry course. One student was omitted due to practical problems scheduling the interview. It is reasonable to assume that these students are among the more interested and able in science, in teacher education. Some physics and chemistry are part of Norwegian compulsory education (Utdanningsdirektoratet, 2009). Our students are therefore supposed to have learned something about substances, molecules and atoms before entering teacher education.

A partial structured clinical interview was used (Novak \& Gowin, 1984; Posner \& Gertzog, 1982). Many of the questions were linked to practical tasks. After the initial demonstration, the student was asked to explain what had happened. If needed, clarifying questions were added. All interviews were tape recorded and some photos were taken.

Questioning always leads to thinking and new ideas. The interviewer consistently tried to avoid any expression that could hint what had happened to the material. He tried to use neutral questions as much as possible (Johnson, 1998b; Johnson \& Gott, 1996). If one look at each task individually, it sometimes would have been desirable to probe deeper with additional questions. That could, on the other hand, introduce new ideas that the students could use in other parts of the interview obscuring their "before questioning" views. If, for example, the interviewer had introduced the idea about particles in connection with the evaporation task and probed deeper, the student might have used this idea in connection with the condensation task. For that reason one sometimes had to take their statements as such. This sometimes resulted in statements that were difficult to interpret during the analysis. What is presented is the author's best judgment. 
The direct discussions about the concepts of matter and substances were postponed to the last part of the interview. Before this direct discussion, the students' use of these concepts explaining some common transformations of substances was examined. The idea was that their use of the concepts in real situations, tells at least as much as a direct discussion.

The students were initially introduced to a selection of (29) different objects, and asked to sort them as they wished, and comment on their choices of categories. They were asked if they could see anything in common to all these objects and comment on that. Later, 8 single-substance objects were picked out and they were asked if they could see anything in common to these and comment on that.

The students then were asked to explain the results and what had happened in 5 practical demonstrations. The following situations were discussed:

a) Evaporation of water. Two dishes were shown, one with a glass lid and with some water, and one without a lid and empty. The student was then told that both had been standing in the room for about a fortnight. Explain what has happened.

b) Two small candles were shown, one long and one short (half burnt). The half burnt was lit for a short time. Explain the missing candle wax of the half burnt candle.

c) Ice was added to a glass of water. After a couple of minutes moisture appeared on the outside. Explain the formation of the moisture.

d) A bit of candle wax was cautiously melted while the student was watching. She was then asked if it could become solid wax again, and about the weight of the liquid wax compared to the solid one.

e) Some coarse table salt was dissolved in a glass of water. After all the salt had disappeared, the student was asked to explain what had happened to it. The weight of the solution compared to water and solid salt was discussed. The possibility to retrieve the salt again was also discussed.

The sequence of these demonstrations is intentional. Evaporation and condensation, and melting and burning of candle wax did not follow directly after each other. The hope was to reduce transfer of new thoughts from one task to the other as a result of questioning.

The interview was finished with a discussion of the meaning of some (Norwegian) words: "stoff" (stuff / matter) and "materiale" (materials), the borderline between "stoff" (stuff / matter) and not "stoff" and the difference between "enkeltstoff (reint stoff)" (a substance) and "stoffblanding" (a mixture).

The interesting parts of the interviews were partly transcribed. Parts giving no relevant information about their views were omitted. The results were coded, sorted and analyzed. The analysis showed that the students could be distributed among four main groups for evaporation and three main groups for dew formation, both including some subgroups.

The analysis showed that the students hold many different ideas. Each student also expresses several ideas and combines them in many different ways. In reality each student (almost) holds her own unique view. Some students, therefore, were difficult to assign to one broad category. The category fitting best was chosen.

\section{RESULTS}

\section{Evaporation at room-temperature}

When asked to explain the disappeared water from a dish without a lid, all students gave some kind of macroscopic explanation. Almost everyone answered evaporation (29/31), or some other relevant macroscopic statements such as "became gas", "it has become vapor", "mixed with the 
Table 1. Groups based upon the students conceptions of evaporation

\begin{tabular}{|c|c|c|c|}
\hline \multicolumn{2}{|r|}{ Category } & \multirow{2}{*}{$\begin{array}{l}\text { Description } \\
\text { Their explanations included statements that could be taken } \\
\text { to mean that the "water" or "vapor" had disappeared. Some of } \\
\text { these statements are difficult to interpret. }\end{array}$} & \multirow{2}{*}{$\begin{array}{c}\begin{array}{c}\text { No. of } \\
\text { students }\end{array} \\
4\end{array}$} \\
\hline & $\begin{array}{c}\text { E1 } \\
\text { Disappear }\end{array}$ & & \\
\hline & $\begin{array}{c}\text { E2 } \\
\text { Adheres to }\end{array}$ & $\begin{array}{l}\text { Vapor / water adheres to, binds to and / or is pulled by some- } \\
\text { thing (wall, ceiling, air, oxygen). } 4 \text { students include some kind } \\
\text { of particles in their explanation }\end{array}$ & 7 \\
\hline & $\begin{array}{c}\text { E3 } \\
\text { Decompose }\end{array}$ & $\begin{array}{l}\text { Water decomposes or splits when it become vapor. } 8 \text { students } \\
\text { explicitly mention hydrogen and oxygen. } 8 \text { include some kind } \\
\text { of particles in their explanation }\end{array}$ & 11 \\
\hline \multirow{3}{*}{ 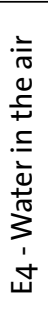 } & $\begin{array}{c}\text { E4m } \\
\text { Macro-statement }\end{array}$ & $\begin{array}{l}\text { Macroscopic statements only. The water has evaporated and } \\
\text { gone into the air }\end{array}$ & 2 \\
\hline & $\begin{array}{l}\text { E4d } \\
\text { Droplets }\end{array}$ & The water has gone into the air as small droplets & 2 \\
\hline & $\begin{array}{l}\text { E4p } \\
\text { Particles }\end{array}$ & $\begin{array}{l}\text { The water has gone into the air. The students' explanations } \\
\text { include some kind of particles (particles, molecules, atoms). } \\
\text { Only } 3 \text { explain the evaporation process (almost) correct using a } \\
\text { molecular model }\end{array}$ & 5 \\
\hline
\end{tabular}

air" etc. In addition everyone gave some other relevant macroscopic statements showing that they think that the water has gone into the air. 27/31 even say that they think the evaporated water still is in the air. All these answers might indicate that the students have a notion of water as a substance and that it somehow maintains its identity even though it "has disappeared" and is now invisible and has become "something else".

However, when they were asked to explain what this means, many had problems answering and several explanations emerged. On the basis of these additional explanations the students could be distributed among 6 groups (Table 1).

4/31 students (Table 1. Category E1 - Disappear) gave statements that could be taken to mean that the "water" or "vapor" had gone to the air and then disappeared, but some of these statements have no obvious interpretation. 3 of these students do not mention that the "water" or "vapor" still is present in the air. A closer look reveals that they either think the water evaporates because of the surroundings / oxygen in the air and then disappears, or that it first goes into the air and then disappears. "Disappear" might then mean that they cannot imagine where it has gone.

7/31 students (Table 1. Category E2 - Adheres to) seem to have problems with the notion that water could stay in the air on its own. It had to adhere to something. 3 different ideas emerged. $3 / 31$ think the water (vapor) rises until it meets the ceiling, the window or something else. First the water goes into the air, but almost all of it leaves again. Only a small fraction may remain in the air. $3 / 31$ say, on a macroscopic level, that the water adheres to, binds to or is pulled into the air. 3/31 think that oxygen plays a role in that respect and pulls the water out. Two of the students combine two of these ideas in their explanation. 4 mention some kind of particles in their explanation.

11/31 students (Table 1. Category E3 - Decompose) seem to have problems with water as a gas. They think water somehow decompose or split when it evaporates. It has to be changed into something else. 8 of the students in this category mention some kind of particles in their explanation. One just states that the water split without any further particulate explanation and two thinks the molecule structure is somehow changed. 8 explicitly mention that it is split into oxygen and 
hydrogen. It should be mentioned, however, that a couple of the students became uncertain about this during the talk.

9/31 students (Table 1. Category E4 - Water in the air) seem to think that the water evaporates, goes into the air and stays there without changing its identity. The following three subcategories emerged:

2/31 students (Table 1. Category E4m - In the air. Macrostatement) state, on a macroscopic level, that the water has evaporated, has gone into the air and that it still remains there. They could not, however, give any further explanation of their notions.

2/31 students (Table 1. Category E4d - In the air. Droplets) seem to think that the water stays in the air, but see it as small water droplets rather than as a gas.

5/31 students (Table 1. Category E4d - In the air. Particles) used some sort of particles when they explained their notions about how the water could stay in the air. It should be mentioned, however, that only 3 of these explain the evaporation process (almost) correct using a molecular model (e.g. "the water molecules separate and float into the air ... as moisture in the air").

17/31 students, from all groups except E1, put forward opinions that could be interpreted as some kind of a particulate view of matter. 3 (all from group E4p) explain the evaporation process (almost) correct (see above). 5 know that the water molecules consist of oxygen and hydrogen atoms, and think that the molecules split in the process. 8 mention molecules, atoms or particles in their explanations, but demonstrate big holes in their knowledge. 2 just mention the formula $\mathrm{H}_{2} \mathrm{O}$.

Some students (12/31), from all the groups, also gave rather neutral macroscopic statements about the evaporation process telling that the water moves from liquid water to the air: "water goes to the air", "the water dissolves, dilutes or mixes with the air".

$11 / 31$ students included a "because explanation" stating that the water evaporated "because of heat", "heat pulls it up", "air is warmer than water and pulls it into the air".

\section{Dew formation}

It is not a trivial task to explain why a layer of water develops outside a glass of water cooled with some ice cubes. One needs a firm grasp of the ideas that there is water in the air, as invisible vapor, and knowledge of that if the temperature lowers below a critical value, the air cannot hold all its water (vapor). One must also acknowledge the idea that "new matter" must come from somewhere and that the substance "water" can vary between different states without changing its identity.

All students rightly knew that the phenomenon is called condensation or dew formation and / or that it is water that is developed on the outside of the cooled glass. 22/31 students, distributed among all groups (see below), also explained that the reason has something to do with the temperature differences (e.g. "has to do with temperature difference", "cold attracts moisture from the air"). When they were asked to explain this further, several notions emerged. On the basis of these additional explanations it is possible to distinguish 3 main groups with some subgroups. These are shown in Table 2.

It should be mentioned, however, that 5/31 students indicated that they had never reflected on the condensation phenomenon. It is something that just happens. Even so, they gave off some considerations on the spot. These considerations are used in this analysis. 
Table 2. Groups based upon the students' conceptions of dew formation

\begin{tabular}{|c|c|c|c|}
\hline \multicolumn{2}{|r|}{ Category } & Description & $\begin{array}{c}\text { No. of } \\
\text { students }\end{array}$ \\
\hline & $\begin{array}{l}\mathrm{C}_{1} \\
\text { Confirmation } \\
\text { of state }\end{array}$ & $\begin{array}{l}\text { Just stating that it is condensation and / or dew formation } \\
\text { and the cause is temperature differences. Very little could } \\
\text { be inferred about the students' view of matter and /or } \\
\text { substances. }\end{array}$ & 5 \\
\hline \multirow{3}{*}{ 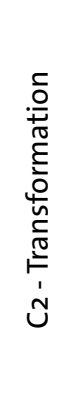 } & $\begin{array}{l}\mathrm{C} 2 \mathrm{e} \\
\text { Energy to water }\end{array}$ & $\begin{array}{l}\text { Some of the students' statements indicate that they think } \\
\text { water is formed from heat or that heat and cold react to } \\
\text { form water. They seem to lack a strict line between energy } \\
\text { and matter. One student mentioned particles. }\end{array}$ & 3 \\
\hline & $\begin{array}{l}\mathrm{C} 2 \mathrm{O} \\
\text { Oxygen to water }\end{array}$ & $\begin{array}{l}\text { Oxygen is involved in water formation. Oxygen is trans- } \\
\text { formed to water or oxygen liberates water. One student } \\
\text { mentioned particles. }\end{array}$ & 2 \\
\hline & $\begin{array}{l}\mathrm{C} 2 \mathrm{~h} \\
\text { Hydrogen and } \\
\text { oxygen to water }\end{array}$ & $\begin{array}{l}\text { Water is formed when oxygen and hydrogen from the air } \\
\text { reunite to water. To these students vapor must be oxygen } \\
\text { and hydrogen gas. } 3 \text { students mentioned particles. }\end{array}$ & 4 \\
\hline \multirow{2}{*}{ 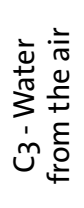 } & $\begin{array}{l}\text { C3m } \\
\text { Macro } \\
\text { statements }\end{array}$ & $\begin{array}{l}\text { The water comes from the air. These students seem to ap- } \\
\text { preciate that there is vapor or water in the air all the time. }\end{array}$ & 12 \\
\hline & $\begin{array}{l}\text { C3p } \\
\text { Particles }\end{array}$ & $\begin{array}{l}\text { The water is formed from water molecules (or particles) } \\
\text { from the air. }\end{array}$ & 5 \\
\hline
\end{tabular}

5/31 students (Table 2. Category C1 - Confirmation of state) just state that it is condensation / dew formation and that the reason is the temperature differences. This is really just a confirmation of the state with new words. Very little could be inferred about their additional notions from this.

9/31 students (Table 2. Category C2 - Transformation) seem to hold a view that the water, the dew, has to be made from something else. These students do not seem to think that water, as a substance, could stay in the air. 3 subgroups emerged.

3/31 students (Table 2. Category C2e - Transformation. Energy to water) gave statements that could indicate an idea that it is energy or heat that had been transformed into water, but their statements are somewhat unclear (e.g. "when heat meets the cold glass, then it is changed into water molecules", "must be some reaction between heat and cold"). This indicates some uncertainty about their ability to preserve the matter / substance. One of these, at the same time, says that the water (vapor) comes from the air. Another mention that oxygen is involved (see below).

2/31 students (Table 2. Category C2o - Transformation. Oxygen to water) think that oxygen is involved (e.g. "it is oxygen in the air on the sides that is cooled and changes form", "the oxygen molecules liberate $\mathrm{H}_{2} \mathrm{O}$ ”).

4/31 students (Table 2. Category C2h - Transformation. Hydrogen and oxygen to water) expressed a notion that hydrogen and oxygen in the air reunite and form water. 3 of these gave additional statements indicating that they think the water (dew) came from the air. To them "water (or vapor)" in the air must mean hydrogen and oxygen. 
The rest of the students (17/31) (Table 2. Category C3 - Water from the air) indicate that they think the water in the dew formation comes from the air. They seem to acknowledge the idea that water is a (single) substance and that it can vary between liquid water and water as vapor in the air. 2 subgroups emerged.

12/31 students (Table 2. Category C3m - Water from the air. Macro statements) state, on a pure macroscopic level, that the water comes from the air. No particles were mentioned.

5 students (Table 2. Category C3m - Water from the air. Particles) included particles in their explanations. 4 of these explicitly mentioned water molecules in the air.

8/31 students, from subgroup C2h and C3m, gave additional macroscopic statements about the process explaining that when the temperature goes down, less water (or vapor) could be held in the air. Another 2/31, from subgroup C3p, included reduced speed of the molecules and/or atoms in their explanations. All these 10 students seem to have a rather good idea about that it is water (vapor) from the air that is turned into water on the outside of the glass. It should be noticed, however, that 3 of these think of "vapor" as hydrogen- and oxygen gas.

Table 3. Correlation between categories. Number of students displaying the different ideas about evaporation and dew formation. Number of students mentioning particles in the different categories, are included.

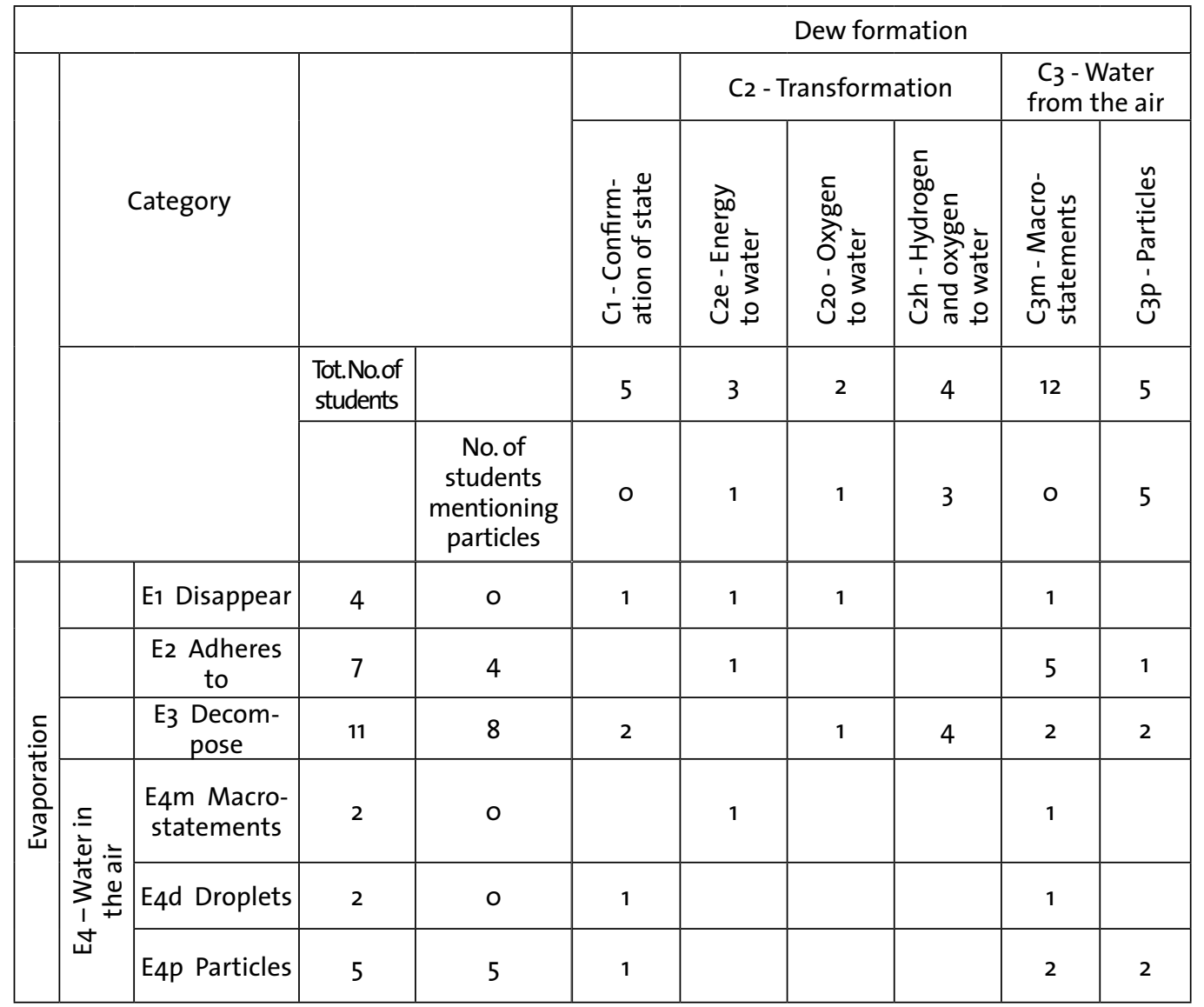




\section{Comparing the students' responses to evaporation and dew formation}

As the students gave several statements each, it is not an easy task to make clear comparisons. Table 3 gives a matrix correlating the different categories from evaporation and dew formation.

One striking aspect of this matrix (Table 3) is the low degree of consistency between the statements given for evaporation and those given for dew formation. The 3 students that imply that the condensed water is formed from energy / heat $(\mathrm{C} 2 \mathrm{e})$ do not mention anything like that in connection with evaporation. Those (2) students stating that the condensed water is made from oxygen or liberated from oxygen (C20) are not the same students that think oxygen is involved in connection with evaporation (E2). Of the 11 students stating that water is decomposed / split into hydrogen and oxygen in connection with evaporation (E3), only 4 use the same idea for dew formation. A total of 20 students mention some kind of particles. Particles are mentioned with regards to evaporation by 17 students, while only 10 mentioned particles in explaining condensation. Only 7 use particles in both instances and only 2 of these use a relatively advanced model for both evaporation (E4p) and condensation (C3p).

\section{Discussions}

\section{Evaporation and dew formation}

Most students start with macroscopic statements that are sensible. They know that the disappearance of water from an open dish, over time, is called evaporation, and that means that the water has gone into the air. They also know that the phenomenon that a liquid is formed outside a cooled glass is called condensation or dew formation and / or that it is water that is developed on the glass.

If one assumes that these statements include all the scientific ideas as oneself, as a scientist, holds, and stops there, one would have the impression that almost all students have understood both the evaporation process and condensation. Probing deeper into what these statements mean to students reveals that many of them hold ideas that differ from the scientific view. This is an illustration of the double translation problem that Johnson and Gott (1996) have discussed. One has a tendency to interpret what is said from one's own point of view. This may generate problems for the students to understand what the teacher (researcher) says, and the teacher may misunderstand the students' responses.

Russel et al. (1989) say: "For a teacher, it may be virtually meaningless to claim that a child "understands evaporation'. It makes more sense to locate that child on a qualitative scale of understanding in relation to various manifestations of the concept" (p. 575). This is the case for our students, too. Some have very faint ideas about what goes on, most have some sensible ideas, but also some nonscientific views, and some have an almost full understanding.

One can only speculate why some students think that the water adheres to something, the ceiling, the windows, the air or oxygen, or is pulled out into the air in connection with evaporation. One explanation could be that they have problems to imagine water "floating" in the air by itself. As Johnson (1998b) and Lee et al. (1993) have demonstrated, water as a gas like air might be a problem. Therefore there has to be an "agent" moving it (Russell, et al., 1989; Tytler \& Peterson, 2000). Also see the discussion of the hydrogen - oxygen problem below.

The idea that oxygen plays a role is also expressed in connection with condensation. This notion seems to be a new one to this investigation for condensation. Oxygen might be a substitute word for air that is reported by Chang (1999). Of the 3 students that mention this, 2 use some kind of particles in their explanations. 
To students not familiar with the intrinsic movements of the water molecules, it is quite natural to think of something "else", some agent, which moves the water. This might be the idea behind the notion that oxygen plays a role. That the water does it "by itself" and stays in the air must be a mystery for them. Also see the discussion of heat below.

The notion that water is split into hydrogen and oxygen when it evaporates is also reported from other investigations (Bar \& Galili, 1994; Bar \& Travis, 1991; Osborne \& Cosgrove, 1983). Both research groups explain it primarily as a result of the use of questionnaires where this option was introduced. In this investigation the notion was introduced by the students themselves without any hinting from the researcher. My guess is that it is a result of sloppy treatment in teaching as well as textbooks, where it is customarily said that water consists of hydrogen and oxygen without specifying that it is the individual water molecules that is built of hydrogen and oxygen atoms. Some kind of important information must have been omitted, so the students infer that the atoms in water easily can split and reunite.

Another explanation could be that if one has a notion of three kinds of substances: solids, liquids and gases (Johnson, 1998a), water can only exist as a liquid and has to split into known gases to become gas. Evaporation as small droplets in the air also avoids the problem of water as a gas.

The view that "water" exists as hydrogen and oxygen when it is "vapor", is also found in connection with condensation. The view has also been reported from other investigations (Bar \& Travis, 1991; Osborne \& Cosgrove, 1983). The water formed is the result of oxygen and hydrogen in the air, reuniting. 3 of these students use some conception of particles in their explanations.

The idea that heat, or the sun, is the cause of evaporation has been reported from several other investigations (e.g. Lindner \& Redfors, 2006a, 2006b; Osborne \& Cosgrove, 1983; Papageorgiou \& Johnson, 2005; Russell, et al., 1989; Tytler \& Peterson, 2000), but is not much discussed.

It is hardly possible to observe any temperature differences in connection with evaporation of water at room temperature. The practical situation is therefore not likely to inspire the students to think of heat as a reason for evaporation. As the focus of this investigation was matter and substance, the statements about heat were not probed any further with follow-up questions. One can therefore only speculate on the ideas behind. Most probably it is a result of schooling, but I would guess that only a few of the students could explain it to any depth. It could also be their answer to the problem of an agent, a "something" that moves the water into the air (Tytler \& Peterson, 2000). See also the discussion above regarding the role air and oxygen play in the evaporation process.

It has been reported that especially younger children think that the water just has disappeared in connection with evaporation (Bar \& Galili, 1994; Bar \& Travis, 1991; Lee, et al., 1993; Osborne \& Cosgrove, 1983). A closer inspection of the statements of the 4 students indicating that the water had disappeared revealed that they might have problems with the idea that water resides in the air. They think it has gone somewhere else, but they don't know for sure where.

It is interesting to note that even though all students seem to know the phenomenon of moisture formed outside a cold glass, several had never reflected upon it. This demonstrates that many people seem to accept phenomena as such and never reflect upon them unless somebody focuses on it. This should be remembered in science teaching. One could never assume that the students know anything about, or, by themselves, have "investigated" well known physical and chemical phenomena.

A little more than half of the students (17/31) gave a reasonably good explanation for condensation, which I think is a good result and higher than for evaporation. High scores have also been 
reported from other investigations (Chang, 1999; Johnson, 1998b; Osborne \& Cosgrove, 1983). However, only 5 of these 17 students explaining condensation well use particles in their explanations.

Most students know that condensation has something to do with temperature differences. This is also reported from other investigations (e.g. Chang, 1999). It is interesting to notice, however, that only $10 / 31$ gave further explanations that were reasonably correct.

The transformation of heat (energy) into water is not a common idea among our students in connection with condensation. Unpublished material shows that it is more common in connection with burning of candles (Håland, submitted). It has also been reported from other investigations (Bar \& Travis, 1991; Osborne \& Cosgrove, 1983). The idea indicates that for these students the border between matter and not matter is somewhat unclear. However, it might also be an unfortunate result of attempts to make the answers sound more scientific. The idea might just be that it has something to do with temperature differences.

Johnson $(1998 b, 2002)$ has pointed out the crucial role the particulate view of matter plays in the understanding of matter and substances and their transformations, but several researchers have demonstrated that students only to a small degree spontaneously make use of particles in their explanations (Johnson, 1998c; Lee, et al., 1993; Nakhleh, et al., 2005).

Altogether 20 students mentioned some kind of particles (particles, molecules, atoms, $\mathrm{H}_{2} \mathrm{O}$ ) in their explanations, 17 in connection with evaporation and 10 in connection with condensation.

Only 3, though, utilized the ideas (almost) correctly in their explanations of evaporation. 7 used their knowledge of water molecules to explain the evaporation as a splitting of water into oxygen and hydrogen. The rest, I think, understands that evaporation has something to do with molecules and atoms, but they have never really understood the concept. For that reason they might try, as Lee et al. (1993) point out, to use "molecular language as a "veneer" without substantially changing their conceptions of matter" (p. 268).

Only 7 students use particles in their explanation of both evaporation and condensation (E4p, $\mathrm{C} 3 \mathrm{p})$, and only 2 of these use a relatively "advanced" model in both instances.

This illustrates the point made by other investigators showing that students can use different ideas to explain related phenomena (e.g. Boujaoude, 1991; Nakhleh \& Samarapungavan, 1999; Nakhleh, et al., 2005). Many of the students in this investigation seem to hold ideas that are "fragmented, diffuse and unconnected" (Nakhleh, 2001, p. 2) and resembles diSessas (1993) p-primes. The other discrepancies between statements given for evaporation and condensation further underscore this point (see "Comparing the students' responses to evaporation and dew formation").

Those 4 students that use the idea about splitting and reunion of water in both instances, plus those 6 that seem to hold an idea of invisible water / vapor in the air (see below), appear to have more consistent views. This agrees with Nakhleh (2001) who points out that some students may hold more coherent (naïve) theories while other students use p-primes. Students may even combine these.

Contrary to this investigation, Johnson (1998b) reports a high degree of correlation between the children's views on evaporation and condensation. One can give at least two possible explanations for this. 1) His interviews come in-between sequences of teaching units on these ideas, and the children have learnt from these. 2) He operates with broader categories that might camouflage differences in the details. 


\section{General views on matter and substances}

The ways the students talk about evaporation and dew formation have shed some light on their general views on matter and substances. 5 aspects will be addressed: matter / non-matter, substances, three types of substances (solids, liquids and gases), phase transitions and water as invisible vapor and a particular view of matter.

In order to understand chemistry (and physics) and what takes place when substances are transformed, it is crucial for the students to differentiate between matter and non-matter. This is not a trivial "borderline". Children (and students) tend to classify material / matter into other ontological categories than scientists do (Chi, Slotta, \& Leeuw, 1994; Nakhleh \& Samarapungavan, 1999). For example, several children would not include liquids and gases in the concept matter (Stavy, 1991).

In this material we find traces of an unclear borderline between matter and non-matter in connection with dew formation. The 3 students who think heat and cold react or heat is transformed into water molecules demonstrate a view of possible matter - energy transformation. This is an example from the transmutation category according to Andersson (1990). Some of the students that state that they have not reflected upon the phenomenon, also seem to be content with the water coming from "nowhere".

Johnson $(1996,2000,2005)$ has discussed the crucial role of the concept of a substance in connection with students' view about the behavior of matter and substances. Students lacking a firm notion of substances that can be recognized by its properties, and being able to change between different states, may also have problems with phase transitions and water as invisible vapor. The latter notion is shown to be crucial for the understanding of evaporation and condensation (Johnson, 1998b; Lee, et al., 1993). It also, most probably, has connections to the idea of three unchangeable types of substances: solids, liquids and gases (Johnson, 1998a).

The interviews indicate that many students have problems with these ideas. Those thinking that the evaporated water has somehow disappeared from the room (E1), and those thinking that it has to adhere to something (oxygen, the ceiling etc) (E2) seem to have difficulties in perceiving water as invisible vapor in the room around us. The same must be true for those thinking water somehow is coming from oxygen in connection with condensation $(\mathrm{C} 2 \mathrm{o})$.

Those thinking that water decompose or split into hydrogen and oxygen when it becomes vapor (E3), and those thinking that water is formed from hydrogen and oxygen in connection with dew formation ( $\mathrm{C} 2 \mathrm{~h}$ ), also must have problems with water as invisible vapor in the air. Instead they "solve the problem" by letting "water as vapor" change into known gasses. At the same time they demonstrate a vague idea about what constitutes a substance and a poor general understanding of change of state.

It might be reasonable to assume that several of these students (E1, E2, E3, C2o, C2h) have an idea of water as a "liquid", and have to seek different ways to explain that it disappear as "vapor".

One interesting question is how many students hold a relatively stable idea about invisible water and / or vapor that goes to the air and stays there during evaporation, and is removed from the air during condensation. Only these students can have some conception of water as an unchangeable substance that can switch between different states. 9 students (E4m, E4d and E4p) give statements that can be interpreted in that direction in connection with evaporation, and 12 (C3m and $\mathrm{C} 3 \mathrm{p}$ ) in connection with condensation. Only 6 gave such statements for both instances. All the other students gave statements pointing to other and non-scientific ideas. Several of these ideas sound scientific, but must be some kind of misinterpretations of instructions. 
Among others Johnson and Nakhleh (e.g. Johnson, 1998b, 2002; Nakhleh, 1994a) argue that a firm grasp of the particulate view of matter is crucial for the understanding of matter and substances and their transformations. Although about $2 / 3$ of the students in this material mention some kind of particles, only 7 use it both in connection with evaporation and condensation and only 2 in an "advanced" way. This indicates that these ideas have little explanatory power for students.

\section{CONCLUSIONS AND IMPLICATIONS FOR TEACHING}

This investigation demonstrates that the phenomena of evaporation and dew formation are not well understood among teacher students. Many of them seem to have many of the same problems as younger students / pupils. Only 6 students out of 31 gave a reasonably correct explanation of both evaporation and dew formation.

The way the students talk about evaporation and dew formation reveals that many of them have problems with the concepts of matter and substances. A few demonstrate an unclear border between matter and not matter, having the idea that matter can transform into energy and vice versa. More students show that they have problems with the concept of substance. Water transforming into invisible vapor and the permanent existence of vapor in the air is one aspect of this. The idea that water can change into oxygen and hydrogen and vice versa is another.

Although many students mentioned some kind of particles, only a few students really tried to use the particulate model of matter to explain these phenomena. Many students seem to need an agent to move the water. Very few take the internal movement of the water molecules into consideration.

Several students use different ideas to explain the scientifically related phenomena of evaporation and dew formation. Their ideas on matter and substances seem to be unstable and rather vague. It is reasonable to conclude, therefore, that to many students their problems with evaporation and dew formation are a result of their conceptions on matter and substances.

The concepts of matter, substances, the particulate view of matter and phase changes constitute central parts of what pupils are expected to learn in compulsory primary and secondary schools in Norway (Utdanningsdirektoratet, 2009). These concepts are also part of the curriculum for the compulsory parts of upper secondary education. According to the official plans it should therefore be well known. Without "hard facts" pointing in other directions, like this investigation, it is therefore quite reasonable to take these concepts as anchoring points (Ausubel, et al., 1978) in introductory chemistry courses for student teachers in colleges and universities.

If one at the outset of the courses assumes that these phenomena and concepts are well understood, one probably at least has a great communication problem. For some of the students the consequence once more has to be to fall back on rote learning with a low degree of understanding. When the student later starts to practice as a teacher he would have difficulties in guiding pupils towards fruitful conceptions of matter and substances. The "bad circle" is repeated once more.

My recommendation is therefore: in the beginning of new chemistry courses for student teachers one has to include some activities that can reveal how well the students understand the above mentioned concepts. If they, as one on basis of this investigation might suspect, have difficulties, the teacher has to reach further back for good anchoring concepts and reorganize the course so that the concepts discussed in this paper are addressed in an understandable way. Håland (2009) give some suggestions for possible anchoring points.

This paper uncovers which views that could be expected among student teachers. Chemistry courses should therefore include sections that can discuss these views and show how they are at odds 
with the scientific views. In particular, problems in viewing water as invisible vapor, but still water, seem to generate problems students relate to in various ways. This aspect, therefore, needs special attention and treatment. Good instructions that expand the substance concept also have to be searched for, and there has to be more focus on particles and the intrinsic movements of particles.

A low percentage of Norwegian student teachers include science courses (that also include some chemistry) in their education. Many science lessons in Norway are therefore done by teachers with no science education beyond secondary school. The low degree of understanding that this investigation reveals, is rather distressing in view of this. Measures to improve the in service teachers' understanding, therefore have to be searched for.

\section{REFERENCES}

Andersson, B. (1990). Pupils' conceptions of matter and its transformations (age 12 - 16). Studies in science education, 18, 53-85.

Andersson, B. (2000). Elevers tänkande och skolans naturvetenskap. Forskingsresultat som ger nya idéer. Göteborg: Enheten för ämnesdidaktik. Institutionen för pedagogik och didaktik. Göteborgs universitet.

Ausubel, D. P., Novak, J. D., \& Hanesian, H. (1978). Educational psychology. A cognitive view (second ed.). New York: Holt, Rinehart and Winston.

Bar, V., \& Galili, I. (1994). Stages of Childrens Views About Evaporation. International Journal of Science Education, 16(2), 157-174.

Bar, V., \& Travis, A. S. (1991). Childrens Views Concerning Phase-Changes. Journal of Research in Science Teaching, 28(4), 363-382.

Boujaoude, S. B. (1991). A study of the nature of students' understanding about the concept of burning. Journal of Research in Science Teaching, 28(8), 689-704.

Chang, J. Y. (1999). Teachers college students' conceptions about evaporation, condensation, and boiling. Science Education, 83(5), 511-526.

Chi, M. T. H., Slotta, J. D., \& Leeuw, N. d. (1994). From things to processes: a theory of conceptual change for learning science concepts. Learning and Instruction, 4, 27-43.

de Vos, W., \& Verdonk, A. H. (1985). A new road to reactions. Part 1. Journal of Chemical Education, 62(3), 238-240.

diSessa, A. A. (1993). Toward an epistomology of physics. Cognition and instruction, 10(2\&3), 105-225.

Driver, R., Squires, A., Rushworth, P., \& Wood-Robinson, V. (1994). Making sense of secondary science. Research into children's ideas. London: Routledge.

Gopal, H., Kleinsmidt, J., Case, J., \& Musonge, P. (2004). An investigation of tertiary students' understanding of evaporation, condensation and vapour pressure. International Journal of Science Education, 26(13), 1597-1620.

Håland, B. (2009). Student teacher conceptions of matter and substances - some results from 31 interviews. In A. Macdonald (Ed.), Planning science instruction: From insight to learning to pedagogical practices. Proceedings of the 9th Nordic Research Symposium on Science Education. 11th - 15th June 2008 Reykjavik, Iceland (pp. 136-138). Reykjavik: Science Education Research Group, School of Education, University of Iceland.

Håland, B. (submitted). Student teachers' conceptions of matter and substances - explaining the missing wax from a half burnt wax-candle. Unpublished manuscript.

Johnson, P. (1996). What is a substance? Education in chemistry, 33(2), 41-42+45.

Johnson, P. (1998a). Children's understanding of changes of state involving the gas state, Part 1: Boiling water and the particle theory. International Journal of Science Education, 20(5), 567-583. 
Johnson, P. (1998b). Children's understanding of changes of state involving the gas state, Part 2: Evaporation and condensation below boiling point. International Journal of Science Education, 20(6), 695-709.

Johnson, P. (1998c). Progression in children's understanding of a 'basic' particle theory: a longitudinal study. International Journal of Science Education, 20(4), 393-412.

Johnson, P. (2000). Developing students' understanding of chemical change: what should we be teaching? Chemical education: research and practice in Europe, 1(1), 77-90.

Johnson, P. (2002). Children's understanding of substances, Part 2: explaining chemical change. International Journal of Science Education, 24(10), 1037-1054.

Johnson, P. (2005). The development of children's concept of a substance: A longitudinal study of interaction between curriculum and learning. Research in Science Education, 35(1), 41-61.

Johnson, P., \& Gott, R. (1996). Constructivism and evidence from children's ideas. Science Education, 80(5), 561-577.

Lee, O., Eichinger, D. C., Anderson, C. W., Berkheimer, G. D., \& Blakeslee, T. D. (1993). Changing Middle School Students Conceptions of Matter and Molecules. Journal of Research in Science Teaching, 30(3), 249-270.

Lindner, A.-C. (2007). Avdunsting och molekyler. En longitudinell studie av hur grundskoleelever utvecklar sina uppfatningar om avdunstingsfenomen. Kristianstad: Institutionen för matematik och naturvetenskap, Høgskolan Kristianstad, Sverige.

Lindner, A.-C., \& Redfors, A. (2006a). Kan grundskoleelvers uppfatningar om fysikaliska fenomen utvecklas gjennom riktade undervisninsatser? Paper presented at the Naturfagdidaktikkens mange facetter. Det 8. nordiske forskersymposium om undervisning i naturfag., Aalborg, Danmark.

Lindner, A.-C., \& Redfors, A. (2006b). Longitudinell studie av hur grundskoleelevers uppfatningar om fysikalska fenomen utvecklas. In L. Häggblom, I. Palmberg \& K. Ström (Eds.), Från natruvetenskap ock specialpedagogik till hållbar utveckling inom lärarutbildningen 2004 (Vol. Rapport 19/2006, pp. 93-107). Vasa: Åbo Akademi.

Nakhleh, M. B. (1992). Why Some Students Don't Learn Chemistry - Chemical Misconceptions. Journal Of Chemical Education, 69(3), 191-196.

Nakhleh, M. B. (1994a). Chemical Education Research in the Laboratory Environment: How Can Research Uncover What Students Are Learning? Journal of chemical education, 71(3), 201.

Nakhleh, M. B. (1994b). Student's Models of Matter in the Context of Acid-Base Chemistry. Journal of chemical education, 71(6), 495-499.

Nakhleh, M. B. (2001). Research: Science and Education - Online Symposium: Piaget, Constructivism, and Beyond - Theories or Fragments? The Debate Over Learners' Naive Ideas About Science. Journal of chemical education, 78(8), 1107. Retrieved from http://pubs.acs.org/doi/ pdf/10.1021/ed078p1107.5

Nakhleh, M. B., \& Samarapungavan, A. (1999). Elementary School Children's Beliefs about Matter. Journal of research in science teaching, 36(7), 777-895.

Nakhleh, M. B., Samarapungavan, A., \& Saglam, Y. (2005). Middle school students' beliefs about matter. Journal of research in science teaching, 42(5), 581-612.

Novak, J. D. (1993). Human constructivism: A unification of psychological and epistemological phenomena in meaning making. International Journal of Personal Construct Psychology, 6, 167-193.

Novak, J. D., \& Gowin, D. B. (1984). Learning how to learn. Cambirdge: Cambridge University Press.

Nussbaum, J., \& Novick, S. (1981). Brainstorming in the classroom to invent a model: a case study. School Science Review, 62(221), 771-778.

Osborne, R. J., \& Cosgrove, M. M. (1983). Children's conceptions of the changes of state of water. Journal of Research in Science Teaching, 20(9), 825-838. 
Papageorgiou, G., \& Johnson, P. (2005). Do particle ideas help or hinder pupils' understanding of phenomena? International Journal of Science Education, 27(11), 1299-1317.

Posner, G. J., \& Gertzog, W. A. (1982). The clinical interview and the measurement of conceptual change. Science Education, 66(2), 195-209.

Russell, T., Harlen, W., \& Watt, D. (1989). Childrens Ideas About Evaporation. International Journal of Science Education, 11(5), 566-576.

Stavy, R. (1988). Childrens Conception of Gas. International Journal of Science Education, 10(5), 553-560.

Stavy, R. (1990). Childrens Conception of Changes in the State of Matter - from Liquid (or Solid) to Gas. Journal of Research in Science Teaching, 27(3), 247-266.

Stavy, R. (1991). Children's Idea About Matter. School science and mathematics, 91(6), 240.

Stavy, R., \& Stachel, D. (1985). Children's conception of changes in the state of matter: from solid to liquid. Archives de Psychologie, 53, 331-344.

Tytler, R., \& Peterson, S. (2000). Deconstructing learning in science-Young children's responses to a classroom sequence on evaporation. Research in Science Education, V30(4), 339-355.

Tytler, R., Prain, V., \& Peterson, S. (2007). Representational issues in students learning about evaporation. Research in Science Education, 37(3), 313-331.

Utdanningsdirektoratet (2009). Kunnskapsløftet - fag og læreplaner. Retrieved 09.01, 2009, from http://www.udir.no/templates/udir/TM_UtdProgrFag.aspx?id=2103 